\title{
Sleep Duration and Results of the Psychomotor Vigilance Test in Construction Workers: A Preliminary Study
}

\author{
$\underline{\text { Ximena Ferrada }}^{1,2}$, Silvia Barrios ${ }^{3}$, Patricia Masalan ${ }^{4}$, Solange Campos ${ }^{5}$, Juan Carrillo ${ }^{6}$ and \\ Yerko Molina ${ }^{7}$
}

1 Universidad del Desarrollo, Santiago, Chile,ximenaferrada@udd.cl

2 Pontificia Universidad Católica de Chile, Santiago, Chile, xferrada@uc.cl

3 Pontificia Universidad Católica de Chile, Santiago, Chile, sbarrios@uc.cl

4 Pontificia Universidad Católica de Chile, Santiago, Chile,mmasalan@uc.cl

5 Pontificia Universidad Católica de Chile, Santiago, Chile, scamposr@uc.cl

6 Unidad de Medicina Respiratoria, Hospital de Calama, Calama, Chile, jcaraz@gmail.com

7 Universidad Adolfo Ibáñez, Santiago, Chile, ypmolina@uc.cl

\begin{abstract}
The construction industry is known by its high rate of accidents. Among the different possible causes of this situation we could find lack of sleep and fatigue. Chronic sleep deprivation is a determining factor in the deterioration of vigilance and alert, and consequently a risk factor for occupational accidents. Fatigue is the answer of our organism to sustained physical and mental effort. Construction workers are prone to fatigue, since their work is characterized by heavy lifting and awkward work postures, so it is relevant to study it more thoroughly, especially regarding its association with sleep efficiency and quality. Regretfully, those topics have been very poorly studied in the construction industry. To understand better these phenomena and to propose strategies to mitigate it and contribute to the reduction of accidents in construction projects, the objective of this study was to understand if there is a relation among sleep duration and fatigue. We worked with 154 male construction workers from one Chilean construction company. To asses sleep quality we used the Pittsburgh Sleep Quality Index. One of their questions asked for average sleep hours in the last 4 weeks. To evaluate fatigue, we used a personal computer version of the Psychomotor Vigilance Test (PC-PVT) that measure alertness and vigilance. This 5-minute test was performed by construction workers on site in the morning. People was classified into groups according to self-reported sleep hours, namely: 79 hours (26\%), 5-7 hours (61.7\%) and $<5$ hours (12.3\%). These results were compared for 3 variables (Mean Reaction Time, $10 \%$ faster and 10\% slower) using an ANOVA test. Differences were found for Mean RT and Slowest $10 \%$, the difference being greater in the group that reported sleeping $<5$ hours, but without statistical significance. Studies with a greater number of subjects and measurements are required throughout the working day.
\end{abstract}

(c) 2020 The Authors. Published by Budapest University of Technology and Economics \& Diamond Congress Ltd Peer-review under responsibility of the Scientific Committee of the Creative Construction Conference 2020.

Keywords: construction workers, fatigue, sleep duration, vigilance

\section{Introduction}

The construction industry has one of the greatest accident rates worldwide [1], and an elevated probability of injuries and occupational illnesses [2]. In Chile, the construction industry has an accident rate of 3.9\%, much higher than the national average of $3.1 \%$, considering 38 casualties due to work related accidents in 2018 [3]. Fatigue is recognized as an accident causation, being a trigger to human error [4]. In the construction industry the impact of fatigue is likely to be more serious, as the construction environment is 
dynamic and risky [5]. In fact, risks on construction sites may be heightened due to inclement weather and mobile equipment, as well as changing and demanding schedules requiring additional work hours [6]. According to Techera et al. [7] the most relevant drivers of fatigue are sleep deprivation and work environment factors such as noise, vibration, and temperature. Sleep deprivation contributes to fatigue, affecting an individual's wellbeing, work performance, and safety [6]. Construction workers are prone to fatigue, since their work is characterized by heavy lifting and awkward work postures, so it is relevant to study it more thoroughly, especially regarding its association with sleep efficiency and quality. Regretfully, those topics have been very poorly studied in the construction industry. To understand better these phenomena and to propose strategies to mitigate it and contribute to the reduction of accidents in construction projects, the objective of this study was to understand if there is a relation among sleep duration and fatigue. The following section of the article will introduce the work methodology carried out in this project, as well as the theoretical framework supporting the main topics studied. Later, the main results of this study, as well as a discussion and conclusion section, will be presented.

\section{Fatigue and Psychomotor Vigilance Test (PVT)}

Fatigue can be described as a reduced ability to perform activities at the desired level due to lassitude or exhaustion of mental and/or physical strength [4]. Fatigue can have different causes such as sleeping a short number of hours and poor sleep quality, and consequences such difficulties concentrating or thinking clearly, and risking falling asleep easily, jeopardizing personal safety or that of others [8]. In fact, because of physiological degradation, the ability of an individual to work safely and efficiently can be severely compromised by fatigue [4]. Related with fatigue are two key physiological factors, loss of sleep and disruption of the circadian cycle. In both cases adequate sleep is the only naturally occurring cure [6]. Then, people who suffer from fatigue acquire a sleep deficit that is probably not noticeable in the early stages, attributing this condition to other variables [8]. Fatigue can be evaluated using the Psychomotor Vigilance Test (PVT) that measure alertness and vigilance. The reaction time (RT) is measure as an indirect assessment of fatigue [9]. PVT is considered the only technology with strong evidence of validation by independent researchers, laboratory studies, and field studies, being considered by most researchers as the eminent method to objectively measure fatigue [9].

\section{Sleep quality}

Currently, the role of sleep has been relegated and the time spent sleeping has been decreasing over the years, as for many the sleep period is seen as a waste of time, even though we know that the consequences of poor sleep quality go beyond simple discomfort, affecting health conditions and life quality [10]. Sleep disturbances are also associated with increased risks of workplace accidents and car accidents due to daytime sleepiness as a result of bad night's sleep [11]. Sleep quality refers not only to the fact of sleeping well at night, but to have an adequate performance the following day. This is important as a determining factor in health and is also a precursor to a good quality of life [12]. To maintain performance and healthy neurobehavioral functioning, the average adult needs at least 7 hours of sleep per night, as recommended by different sleep organizations, but many people do not sleep so many hours, transforming chronic sleep loss in a significant public health issue [13]. Sleep deprivation can result from factors such as lifestyle, stress, poor sleep habits, and sleep disorders such as sleep apnea and restless legs' syndrome, putting people at higher risk of accidents [6]. To understand better the situation of people regarding sleep quality we can applied different psychometric instruments, such as the Pittsburgh Sleep Quality Index (PSQI). The PSQI is an instrument that measures the quality of sleep and its alterations based on references from the last 30 days. It is a standardized instrument used in the detection and evaluation of sleep problems developed by Buysse, Reynolds, Monk, Berman and Kupfer in 1989 in the United States, with the objective of evaluating the quality of sleep and its clinical alterations. It has questions that are organized into 7 aspects such as subjective sleep quality, latency, duration, efficiency, sleep disturbances, use of sleep medication, daytime dysfunction [14]. 


\section{Research methodology}

An observational, cross-sectional relational study was carried out in May 2019 whose population corresponded to workers in five construction projects in Santiago, Chile $(N=1,700)$. A random sampling was performed, reaching a sample size of 154 subjects. To be included in the study the workers must have been in the company for more than 1 month and have at least 1 year of work experience in the field. The exclusion criteria include the following: a) have had a surgical intervention that required general anesthesia in the last three months b) have a life expectancy of less than three months, c) have addiction to illegal drugs and/or alcohol; d) people who work shift systems (since it alters wakeful sleep cycles), e) people with living conditions that prevent them from sleeping through the night (for example, having dependent people in their care) and f) people with psychiatric disorders (except depression). The research team visited each one of the construction projects to interview the workers. In each visit the following information was gather a) Sociodemographic information such as sex, occupation, schooling, and marital status, that were asked through a questionnaire designed for the study; b) Quality and quantity of sleep. This was evaluated through the application of the Pittsburgh Sleep Quality Index (PSQI) through an interview. Here, the score ranges from 0 to 21. A score greater than 5 is rated as a poor sleeper; and c) Fatigue level. To measure this variable, we used a personal computer version of the Psychomotor Vigilance Test (PC-PVT) that indicates the reaction levels that are homologated to the fatigue level.

\section{Results}

The sample included 154 male construction workers. The age of the participants fluctuated between 20 and 72 years with an average of 44.17 years. Regarding the years of study, the average number of years was 10.47. Concerning nationality, $82.5 \%$ declare themselves Chilean, followed by $8.4 \%$ of Peruvian workers, $3.9 \%$ of Haitians and 3.2\% of Colombians. The rest is divided between Argentines, Ecuadorians, and Venezuelans. Most construction workers declare that their perception of health is good (51.9\%), $22.7 \%$ say they have very good or excellent health, while $25.4 \%$ consider that their health is fair or poor. $50.6 \%$ do little or no physical activity, while only $18.2 \%$ do not declare themselves sedentary (Table 1). In relation to comorbidity, the declared condition more prevalent in the sample is hypertension (13.0\%) followed by diabetes (5.8\%) and diseases of the musculoskeletal system (3.2\%). There were no cases of stroke, arrhythmia, or heart failure. It is highlighted that $60.2 \%$ of the sample is overweight or obese and $36.4 \%$ have a high cardiovascular risk (CVR) (Table 1). Regarding sleep-related events, $24.7 \%$ of the interviewed construction workers sleep the average hours, that is, between 7 and 8 hours, while $74 \%$ sleep less than 7 hours. The most prevalent condition is the presence of snoring (56.5\%), followed by fatigue (44.8\%) and drowning (40.3\%), as shown in Table 2.

Regarding $44.8 \%$ of the workers who declared fatigue, there is no evidence of a relationship between hours of sleep with fatigue ( $t=1.618 ; p=0.108$ ), this means that the presence of fatigue is distributed equally among those people who sleep less than 7 hours, between 7 and 8 hours and more than 8 hours, that is, the hours asleep versus the presence or not of fatigue are independent (Table 3 ). When analysing the quality of sleep according to Pittsburgh, only $23.4 \%$ of the sample presented a good sleep ( $<5$ Pittsburgh) (Table 4). 76.6\% report some degree of difficulty sleeping. Of these, 37.7\% (5-7 Pittsburgh) could present more than some unsuitable condition for quality sleep, that is, snoring or nightmares, among other conditions that occur less than once a week for the last month. Similarly, another $37.7 \%$ could present these conditions one or more times a week. When analysing the performance parameters in the psychomotor surveillance test (PC-PVT), a significant association between the age group of 20-29 years was observed with a better performance in the PC-PVT in all the compared parameters (Mean RT, Fastest $10 \%$ and Slowest10\%) (see Table 5). Likewise, it is observed that workers with higher educational level have better performance of the PC-PVT in all the parameters, as shown in Table 6. Regarding the number of hours of sleep, a better performance in the test was observed in the group that reported sleeping between 5-7 hours per day on average, although it reached statistical significance only in the Fastest10\% (results of the 90th fastest percentile) (see Table 7). 
Table 1. Sociodemographic and health characteristics of the sample.

\begin{tabular}{lll}
\hline Age (average) & & 44.17 (SD: 12.72) \\
\hline Schooling (average years) & & 10.47 (SD: 3.31) \\
\hline Perception of Health & Excellent- Very Good & $22.7 \%$ \\
& Good & $51.9 \%$ \\
& Regular- Bad & $25.4 \%$ \\
\hline Exercise & Not done & $50.6 \%$ \\
& $>$ 3 times a week & $18.2 \%$ \\
\hline Comorbidity & Arterial hypertension & $13.0 \%$ \\
& Diabetes & $5.8 \%$ \\
& Acute myocardial infarction & $1.3 \%$ \\
& Locomotor system & $3.2 \%$ \\
& Respiratory & $0.6 \%$ \\
& Neurological & $0.6 \%$ \\
& Mental health & $0.6 \%$ \\
& Obesity (BMl> 30) & $32.7 \%$ (range 30.05-40.82) \\
& Overweight (BMI 25-29.9) & $27.5 \%$ (range 25.12-29.83) \\
& Moderate CVR (Waist circumference> 94) & $28.6 \%$ (range 95-101.5) \\
& High CVR (Waist circumference> 102) & $36.4 \%$ (range 102-126)
\end{tabular}

Table 2. Features related to sleep events.

\begin{tabular}{lll}
\hline Sleep hours & $<7$ hours & $74.0 \%$ \\
& $7-8$ hours & $24.7 \%$ \\
& $>8$ hours & $1.3 \%$ \\
\hline Events during sleep & Snore & $56.5 \%$ \\
& Drown & $40.3 \%$ \\
\hline Daytime conditions & Fatigue & $44.8 \%$ \\
\hline
\end{tabular}

Table 3: Relationship between hours of sleep and declared fatigue.

\begin{tabular}{lccccc}
\hline & Fatigue & $\mathrm{N}$ & Mean & SD & \\
\hline Hours of sleep & Yes & 69 & 5.72 & 1.24 & $\mathrm{t}=1.618$ \\
& No & 85 & 6.04 & 1.19 & $\mathrm{P}=0.108$ \\
\hline
\end{tabular}

Table 4. Sleep quality according to Pittsburgh.

\begin{tabular}{llcccc}
\hline Pittsburgh & & Frequency & Percentage & Valid percentage & Accumulated percentage \\
\hline Valid & $<5$ & 36 & 23.4 & 23.4 & 23.4 \\
& $5-7$ & 58 & 37.7 & 37.7 & 61.0 \\
& $8-14$ & 58 & 37.7 & 37.7 & 98.7 \\
& $>15$ & 2 & 1.3 & 1.3 & 100.0 \\
& Total & 154 & 100.0 & 100.0 & \\
\hline
\end{tabular}


Table 5. Comparative results of performance parameters in PC-PVT according to Age Group (ANOVA).

\begin{tabular}{lcccccc}
\hline Parameters & $\begin{array}{c}20-29 \text { years } \\
\mathrm{n}=29\end{array}$ & $\begin{array}{c}30-39 \text { years } \\
\mathrm{n}=24\end{array}$ & $\begin{array}{c}40-49 \text { years } \\
\mathrm{n}=41\end{array}$ & $\begin{array}{c}50-59 \text { years } \\
\mathrm{n}=40\end{array}$ & $\begin{array}{c}60-75 \text { years } \\
\mathrm{n}=18\end{array}$ & $\mathrm{p}$-Value \\
\cline { 2 - 6 } & Average $( \pm \mathrm{SD})$ & Average $( \pm \mathrm{SD})$ & Average $( \pm \mathrm{SD})$ & Average $( \pm \mathrm{SD})$ & Average $( \pm \mathrm{SD})$ & \\
\cline { 2 - 6 } Mean RT & $274.54(26.21)$ & $290.32(35.32)$ & $320, .72(119.01)$ & $305,41(37.76)$ & $341.88(63.24)$ & 0.01 \\
Fastest10\% & $208.86(16.73)$ & $212.27(17.09)$ & $226.93(38.56)$ & $223,04(22.60)$ & $241.94(27.03)$ & 0.00 \\
Slowest10\% & $402.70(52.26)$ & $488.44(171.65)$ & $554.51(328.58)$ & $529,89(178.05)$ & $669.57(290.51)$ & 0.00 \\
\hline
\end{tabular}

Table 6. Performance results in the parameters of the PC-PVT according to Educational Level.

\begin{tabular}{lcccc}
\hline Parameters & $\begin{array}{c}\text { Low }(<8 \text { years }) \\
\mathrm{n}=44\end{array}$ & $\begin{array}{c}\text { Medium }(8-12 \text { years }) \\
\mathrm{n}=85\end{array}$ & $\begin{array}{c}\text { High }(>12 \text { years }) \\
\mathrm{n}=25\end{array}$ & \multirow{2}{*}{$\mathrm{p}$-Value } \\
\cline { 2 - 4 } & Average $( \pm \mathrm{SD})$ & Average $( \pm \mathrm{SD})$ & Average $( \pm \mathrm{SD})$ & \\
\cline { 2 - 4 } Mean RT & $327.99(74.67)$ & $301.14(77.92)$ & $277.50(26.01)$ & 0.02 \\
Fastest10\% & $236.44(37.73)$ & $217.98(21.24)$ & $208.93(18.67)$ & 0.00 \\
Slowest10\% & $599.10(284.63)$ & $505.42(229.81)$ & $431.83(104.96)$ & 0.01 \\
\hline
\end{tabular}

Table 7. PC-PVT performance results according to self-reported sleep hours.

\begin{tabular}{lcccc}
\hline Parameters & $\begin{array}{c}<\text { hours } \\
\mathrm{n}=52\end{array}$ & $\begin{array}{c}5-7 \text { hours } \\
\mathrm{n}=84\end{array}$ & $\begin{array}{c}7-9 \text { hours } \\
\mathrm{n}=18\end{array}$ & \multirow{2}{*}{$\mathrm{p}$-Value } \\
\cline { 2 - 4 } & Average $( \pm \mathrm{SD})$ & Average $( \pm \mathrm{SD})$ & Average $( \pm \mathrm{SD})$ & \\
\cline { 2 - 4 } Mean RT & $314.63(103.57)$ & $294.23(35.42)$ & $327.19(89.03)$ & 0.11 \\
Fastest10\% & $222.32(29.31)$ & $217.44(19.71)$ & $240.56(47.43)$ & 0.01 \\
Slowest10\% & $544.40(305.96)$ & $499.33(164.38)$ & $548.02(304.27)$ & 0.49 \\
\hline
\end{tabular}

\section{Discussion}

Regarding clinical parameters, the average body mass index (BMI) is similar, and the waist circumference is lower than the study of Chilean workers [15]. Compared to the general Chilean population, the proportion of overweight workers is lower and the proportion of obese is similar. Regarding the suspicion of hypertension, risk of diabetes, and risk of myocardial infarction, the prevalence of workers are lower than the figures found in the Chilean population in the National Health Survey of 2017 [16]. Probably these better figures are explained because the sample is made up of people who are working in a job and therefore in health conditions that allow them to do it. Regarding sleep hours, $74 \%$ of workers sleep less than 7 hours. The situation of Chilean workers is worrying since Powell and Copping [6] shows that those who sleep less than 8 hours have an $8.9 \%$ increased risk of accidents. Also, they shows daytime fatigue, psychomotor impairment, deterioration of physical and psychological health and poor academic or work performance [17]. Regarding the quality of sleep evaluated by Pittsburgh, the study by Baron [18] reports that $61 \%$ of workers in manufacturing companies present sleep problems with a score greater than 5 , a figure lower than the findings of this study where a $76.6 \%$ report some degree of sleep problems. Workers with Pittsburgh greater than 5 have a 1.78 times more risk of occupational injuries compared to those with a rank less than 5 [19]. In the present study, $44.8 \%$ of the workers felt fatigued when carrying out their daily activities. These results are superior to that of Uehli et al. [20] where only $22 \%$ report high levels of fatigue. Observing the results obtained in the psychomotor surveillance test (PC-PVT), it is observed that the higher the educational level, the better performance is achieved in all the parameters, which coincides with that indicated by Wendt et al.[11]. Although it seems that there is a relationship between sleep duration and fatigue, this study is not conclusive to report this relationship, given that $44.8 \%$ of workers who declared fatigue did not have significant differences regarding the number of hours asleep when compared between groups sleeping less than 7 hours, between 7 and 8 hours or more than 8 hours. To conclude if there is a relationship, more studies are required to delve into fatigue, its forms of measurement and the differentiation that must exist between the concepts of fatigue and drowsiness. 


\section{Conclusion}

This study sought to describe sleep quality in construction workers, finding that less than a quarter of the sample $(23.4 \%)$ presented good sleep quality (Pittsburgh $<5$ ) and two thirds sleep less than 7 hours. People between 20 and 29 years of age, with a higher educational level and who slept between 5 and 7 hours, presented the best performance in psychomotor surveillance evaluated by the PC-PVT test, which is the objective means of evaluating fatigue. Even though most of the workers had a positive perception of their health, they presented different chronic health problems that affect their life quality and their performance at work, especially in relation to overweight, obesity and cardiovascular risk. Although this is representative of what is happening in the country, given the great physical effort that working in construction means, it is important that these conditions are faced in a structured way, ideally from the construction company itself, as a benefit for its workers. To better understand the situation experienced in construction projects, more in-depth studies are required to better assess the health status of workers. It is important that construction companies are aware of the importance that sleep quality has in their workers, both personally and at work. In the latter case, the impact on safety and the accident rate has been widely demonstrated, making it relevant to carry out programs that educate workers on these issues to change their behaviour. Given the above, in the next stages of this research, interventions will be carried out with workers to provide them with tools to improve their sleep quality, and then evaluate their impact on their fatigue levels. In this study, fatigue was measured in the morning, which could have influenced performance. In order to have a better understanding of the phenomenon and have more information to compare the perception of fatigue and daytime sleepiness of workers, it is necessary to make more measurements with the PC-PVT at different times during the workday.

\section{References}

[1] A. C. Escamilla, M. de las N. G. García, and N. L. Pérez, "Static load behavior and energy absorption of safety guardrails for construction works," Revista de la Construcción, vol. 15, no. 2, pp. 46-54, 2016. https://doi.org/10.4067/S0718-915X2016000200005

[2] J. Yuan, W. Yi, M. Miao and L. Zhang, "Evaluating the Impacts of Health, Social Network and Capital on Craft Efficiency and Productivity: A Case Study of Construction Workers in China," vol. 15, no. 2, 2018. https://doi.org/10.3390/ijerph15020345

[3] SUSESO, "Informe anual estadisticas de seguridad social 2018," Santiago, Chile, 2019.

[4] U. Techera, M. Hallowell, R. Littlejohn, "Worker Fatigue in Electrical-Transmission and Distribution-Line Construction," Journal of Construction Engineering and Management, vol. 145, no. 1, pp. 1-9, 2019. https://doi.org/10.1061/(ASCE)CO.1943-7862.0001580

[5] D. Fang, Z. Jiang, M. Zhang, and H. Wang, "An experimental method to study the effect of fatigue on construction workers ' safety performance," Safety Science, vol. 73, pp. 80-91, 2015. https://doi.org/10.1016/j.ssci.2014.11.019

[6] R. Powell and A. Copping, "Sleep deprivation and its consequences in construction workers," Journal of Construction Engineering and Management, vol. 136, no. 10, pp. 1086-1092, 2010. https://doi.org/10.1061/(ASCE)CO.1943-7862.0000211

[7] U. Techera, M. Hallowell, N. Stambaugh and R. Littlejohn, "Causes and Consequences of Occupational Fatigue: Meta-Analysis and Systems Model”, Journal of Occupational Fatigue, vol. 58, no. 10, pp. 961-973, 2016. https://doi.org/10.1097/jom.0000000000000837

[8] H. Cajamarca, E. Londoño, and A. M. López, "Diseño de un mecanismo de control para la fatiga y cansancio en las jornadas de conducción como factor de accidentalidad para la empresa RG Group S.A.S.," Corporación Universitaria Minuto de Dios, 2018.

[9] U. Techera, M. Hallowell, R. Littlejohn, and S. Rajendran, "Measuring and Predicting Fatigue in Construction : Empirical Field Study," vol. 144, no. 8, pp. 1-9, 2018. https://doi.org/10.1061/(ASCE)CO.1943-7862.0001513

[10] D. Lira and N. Custodio, "Los trastornos del sueño y su compleja relación con las funciones cognitivas," Revista de NeuroPsiquiatría, vol. 81, no. 1, pp. 20-28, 2018. https://doi.org/10.20453/rnp.v81i1.3270

[11] A. Wendt et al., "Sleep disturbances and daytime fatigue: Data from the Brazilian national health survey, 2013," Cadernos de Saúde Pública, vol. 35, no. 3, pp. 1-12, 2019. https://doi.org/10.1590/0102-311x00086918

[12] P. Borquez, "Calidad del sueño, somnolencia diurna y salud autopercibida en estudiantes universitarios," Eureka, vol. 8, no. 1, pp. 80-91, 2011.

[13] N. Goel, "Neurobehavioral Effects and Biomarkers of Sleep Loss in Healthy Adults," Current Neurology and Neuroscience Reports, 17, 2017. https://doi.org/10.1007/s11910-017-0799-x

[14] Y. Luna-Solis, Y. Robles-Arana, and Y. Agüero-Palacios, "Validation of the Pittsburgh Sleep Quality Index in a Peruvian Sample," Anales de Salud Mental, no. 2, pp. 23-30, 2015.

[15] J. Salinas, L. Lera, C. G. González, E. Villalobos, and F. Vio, "Estilos de vida, alimentación y estado nutricional en trabajadores de la construcción de la Región Metropolitana de Chile," Revista Médica de Chile, vol. 142, no. 7, pp. 833-840, 2014. https://dx.doi.org/10.4067/S0034-98872014000700003

[16] Subsecretaría de Salud Pública, Departamento de Epidemiologia, Division de Planificación Sanitaria, "Encuesta Nacional de Salud 2016-2017 Primeros resultados," 2017.

[17] M. Martínez, “¿Cuánto hay que dormir para un sueño saludable?”, Revista de Neurología, vol.63, pp. S7, 2016.

[18] M. A. Barón, "Quality of sleep in workers from a manufacturing company with shift work," Revista Red de Investigación en Salud en el Trabajo, vol. 2, pp. 48-50, 2019.

[19] K. Uehli et al., "Sleep quality and the risk of work injury: A Swiss case-control study," Journal of sleep research, vol. 23, no. 5, pp. 545-553, 2014. https://doi.org/10.1111/jsr.12146

[20] L. Huauya, "Indicadores de salud ocupacional en operarios de construcción civil de Lima Metropolitana," Universidad Ricardo Palma Facultad de Ingeniería, 2019. 